\section{(C) OPEN ACCESS}

\title{
SAFE study (Safety and efficacy Analysis of FRED Embolic device in aneurysm treatment): 1-year clinical and anatomical results
}

\author{
Laurent Pierot, ${ }^{1}$ Laurent Spelle, ${ }^{2}$ Jérôme Berge, ${ }^{3}$ Anne-Christine Januel, ${ }_{1}^{4}$ \\ Denis Herbreteau ${ }^{5}$ Mohamed Aggour, ${ }^{6}$ Michel Piotin, ${ }^{7}$ Alessandra Biondi, ${ }^{8}$ \\ Xavier Barreau, ${ }^{3}$ Charbel Mounayer, ${ }^{9}$ Chrisanthi Papagiannaki, ${ }^{10}$ Jean-Paul Lejeune, ${ }_{1}^{11}$ \\ Jean-Yves Gauvrit, ${ }^{12}$ Anne-Laure Derelle, ${ }^{13}$ Emmanuel Chabert, ${ }^{14}$ Vincent Costalat ${ }^{15}$
}

For numbered affiliations see end of article.

\section{Correspondence to}

Dr Laurent Pierot, Department of Neuroradiology, Hôpital

Maison-Blanche, Reims cedex 51092, France; Ipierot@gmail. com

Received 13 July 2018 Revised 8 August 2018 Accepted 9 August 2018 Published Online First 8 October 2018
Check for updates

(C) Author(s) (or their employer(s)) 2019. Re-use permitted under CC BY-NC. No commercial re-use. See rights and permissions. Published by BMJ.

To cite: Pierot $L$, Spelle $L$, Berge J, et al. J Neurolntervent Surg 2019;11:184-189.

\section{ABSTRACT}

Background and purpose Flow diversion is an innovative and increasingly used endovascular treatment for intracranial aneurysms. Its initial evaluation with the first devices available showed good efficacy of this treatment with variable safety results. The Flow Direction Endoluminal Device (FRED) has a specific design and was evaluated in a single-arm, multicenter, prospective, Good Clinical Practice study: SAFE (Safety and efficacy Analysis of FRED Embolic device in aneurysm treatment). This analysis reports clinical results at 1 year and anatomical results at 6 months and 1 year.

Methods Patients with unruptured and recanalized aneurysms located in the anterior circulation treated with FRED and FRED Jr were prospectively included. A Clinical Event Committee and a Core Laboratory independently evaluated clinical outcome and anatomical results.

Results Thirteen interventional neuroradiology centers included 103 patients/aneurysms. Aneurysm locations were supraclinoid internal carotid artery (ICA) in 71 $(68.9 \%)$, cavernous ICA in $15(14.6 \%)$, anterior cerebral or anterior communicating artery in $9(8.7 \%)$, and middle cerebral artery in $8(7.8 \%)$. Most aneurysms were small $(<10 \mathrm{~mm})$ in 71 patients $(68.9 \%)$. Cumulative 1 -year mortality and morbidity rates were 2/103 (1.9\%) and $3 / 103(2.9 \%)$, respectively, one death being related to cancer. At 1 year, anatomical results were: complete occlusion in 66/90 patients $(73.3 \%)$, neck remnant in $7 / 90$ patients $(7.8 \%)$, and aneurysm remnant in $17 / 90$ patients (18.9\%).

Conclusions SAFE study analysis at 1 year confirms the excellent safety profile of the FRED device for aneurysm treatment, with low morbidity and mortality rates (2.9\% and $1.9 \%$, respectively) and demonstrates its efficacy (adequate occlusion in 73/90 (81.1\%)).

Clinical trial registration Unique identifier: NCT02921698; Results.

\section{INTRODUCTION}

Flow diversion is an innovative endovascular treatment that uses dense mesh stents named flow diverters placed in front of the aneurysm neck in order to divert the flow toward the parent artery and to decrease the flow into the aneurysm inducing intra-aneurysmal thrombosis. Flow diversion is an increasingly used technique in the endovascular management of intracranial aneurysms. ${ }^{1-3}$ The Pipeline flow diverter (Medtronic, Minneapolis, Minnesota, USA) was the first device to be systematically evaluated in the Pipeline for Uncoilable or Failed Aneurysms (PUFS) study, dedicated to internal carotid artery (ICA) aneurysms, showing its good safety and efficacy. ${ }^{4}$

Indications for flow diverters are not completely established. Their use in the posterior fossa, for bifurcation aneurysms, or for fusiform aneurysms is still a matter of debate. ${ }^{5} 6$ Their effectiveness compared with other endovascular treatment techniques is clearly demonstrated in large and giant aneurysms as well as recurrent aneurysms. ${ }^{78}$ They are increasingly used in small aneurysms. ${ }^{9}$ As dual antiplatelet treatment is needed to reduce thromboembolic complications, their indications for ruptured aneurysms are limited.

Besides the usual periprocedural complications (thromboembolic events, intraoperative rupture), more specific complications are seen after flow diversion: occlusion of collateral branches covered by the flow diverter, in-stent thrombosis or stenosis, delayed aneurysm rupture, or delayed remote hematomas..$^{10} 11$

The Flow Direction Endoluminal Device (FRED) is a double-layer flow diverter with a stent-like outer layer and a flow diverter part inside the stent. This design enhances the navigability of the device, especially in tortuous anatomy and apposition of the device to the arterial wall, a key point in achieving aneurysm occlusion. According to the specific design of different flow diverters, these devices require careful evaluation for assessment of safety and efficacy. Limited evaluation of FRED is available singularly in multicenter, prospective studies. $^{12-15}$

The Safety and efficacy Analysis of FRED Embolic device in aneurysm treatment (SAFE) trial is a single-arm, multicenter, prospective, Good Clinical Practice study conducted in France to precisely analyze the safety and efficacy of this device. The safety results at 6 months have already been analyzed and published, showing low mortality $(1.0 \%)$ and morbidity $(2.0 \%)$ at 6 months. ${ }^{16}$ The present analysis focuses on safety data at 1 year and anatomical results at 6 months and 1 year. 


\section{MATERIALS AND METHODS}

SAFE is a single-arm, prospective, multicenter, observational study for the evaluation of aneurysm treatment with the FRED device in 13 interventional neuroradiology centers in France.

SAFE received national regulatory authorization, including approvals in France from the Consultative Committee of Information Processing in Healthcare Research programme (CCTIRS), the Reims Institutional Review Board, and the National Commission for Data Processing and Freedom (CNIL). All included patients were fully informed of the study objectives by the investigators and provided with a patient information sheet. Patients agreed to anonymized data collection in the study frame. According to French law, no written informed consent was necessary.

\section{FRED and FRED Jr}

FRED and FRED Jr systems (Microvention, Aliso Viejo, California, USA) have been previously described. ${ }^{16}$ Briefly they have a self-expanding nickel titanium, single wire braid, closed-cell paired-stent design. The external stent permits accurate positioning of the device while the internal lower porosity stent enables flow diversion. The FRED and FRED Jr systems have several radiopaque markers. FRED is delivered through a $0.027 "$ microcatheter (Headway 27, Microvention) and FRED Jr through a 0.021" microcatheter (Headway 21, Microvention). Both systems can be recaptured until $80 \%$ of deployment. FRED and FRED Jr exist in various diameters (FRED between 3.5 and $5.5 \mathrm{~mm}$; FRED Jr between 2.5 and $3.00 \mathrm{~mm}$ ) and lengths.

\section{Study design}

The study design has been previously described. ${ }^{16}$

Briefly, primary and secondary objectives of SAFE are defined to evaluate the feasibility, safety, and efficacy of the FRED and FRED Jr systems: description of peroperative and postoperative complications, and clinical and anatomical outcomes at 6 and 12 months.

Unruptured and recanalized aneurysms were included. Patients were not included if they had an intracranial hemorrhage within 30 days before the procedure, or had already had an aneurysm treated, located on the same vessel, or if the aneurysm was located in the posterior circulation.

SAFE was conducted according to Good Clinical Practice rules:

- All data were controlled by independent clinical research associates.

- All adverse events were independently evaluated by the Clinical Event Committee, which included a vascular neurosurgeon and an interventional neuroradiologist.

- Anatomical results were independently evaluated by a Core Laboratory (Core Lab), which included two interventional neuroradiologists.

A minimal prior experience of five flow-diversion procedures, whatever the medical device, and two procedures with FRED, was requested for each investigational site.

\section{Procedural modalities}

Preoperative, intraoperative, and postoperative antiplatelet therapy was managed in each center. Antiplatelet activity testing was not required in the study protocol. Treatment with additional devices (balloons, coils, and stents) could be performed, if deemed necessary by the treating physician.

\section{Data collection}

Each center completed a patient file with demographic (patient's age and gender), aneurysm (rupture status, location, size, and neck size), and procedural data.

Clinical evaluation, including modified Rankin Scale (mRS) score, was performed before treatment, at hospital discharge, at 30 days ( \pm 7 days), at 6 months ( \pm 3 months), and at 12 months ( -3 months/ +6 months). Six-month ( \pm 3 months) and 12-month ( -3 months +6 months) vascular imaging data were collected. Vascular imaging was performed according to usual practice (digital subtraction angiography, magnetic resonance angiography, computed tomographic angiography). Data from retreatment procedures were also collected.

\section{Data analysis}

The outcome of the complications was independently evaluated by the Clinical Event Committee, and the complications with clinical impact were defined as any complication that resolved with sequelae, was unresolved at study completion or of unknown outcome. The complications up to 6 months already published were updated. ${ }^{16}$

Morbi-mortality was defined as an mRS score $>2$.

Anatomical results were evaluated by an independent Core Lab, postoperatively, at 6 months ( \pm 3 months), and at 12 months ( -3 months/ +6 months) using a three-grade scale: complete occlusion, neck remnant, or aneurysm remnant. A direct vascular imaging comparison was also performed between postoperative and 6 -month results, and between 6 and 12 months to determine if aneurysm occlusion was better, stable, or worse. The Core Lab did not evaluate the quality of device deployment or its vessel wall apposition. It did evaluate the status of the parent artery with a three-grade scale: no stenosis or stenosis $<50 \%$, stenosis $\geq 50 \%$, or complete occlusion.

\section{Statistical analysis}

At the time of preparation of the SAFE study, only one prospective, multicenter study had been published (PUFS). ${ }^{4}$ The SAFE study was designed using the results of PUFS (number of patients, endpoints, and so on).

The statistical analysis was performed on the full analysis set (FAS). The FAS consisted of all subjects who met all inclusion and non-inclusion criteria and had undergone at least one treatment with the intention of implanting the FRED or FRED Jr device. The efficacy population consisted of patients implanted with a FRED or FRED Jr device. The two different groups are described in figure 1.

The overall device safety was assessed from the 12-month mortality and morbidity rates, based on the FAS population. Missing data or early withdrawals were replaced by the last observation carried forward method.

The efficacy criteria defined by the rate of aneurysm occlusion, the evolution of occlusion between postprocedure and 6 months, and between 6 and 12 months, and the status of the parent artery were reported for the efficacy population.

Analyses were performed using statistical analysis software (SAS version 9.2, SAS Institute, Cary, North Carolina, USA).

\section{RESULTS}

\section{Patient and aneurysm population}

Between July 2014 and June 2016, 113 patients were screened in 13 French interventional neuroradiology centers (figure 1). Nine patients did not meet inclusion and non-inclusion criteria. 


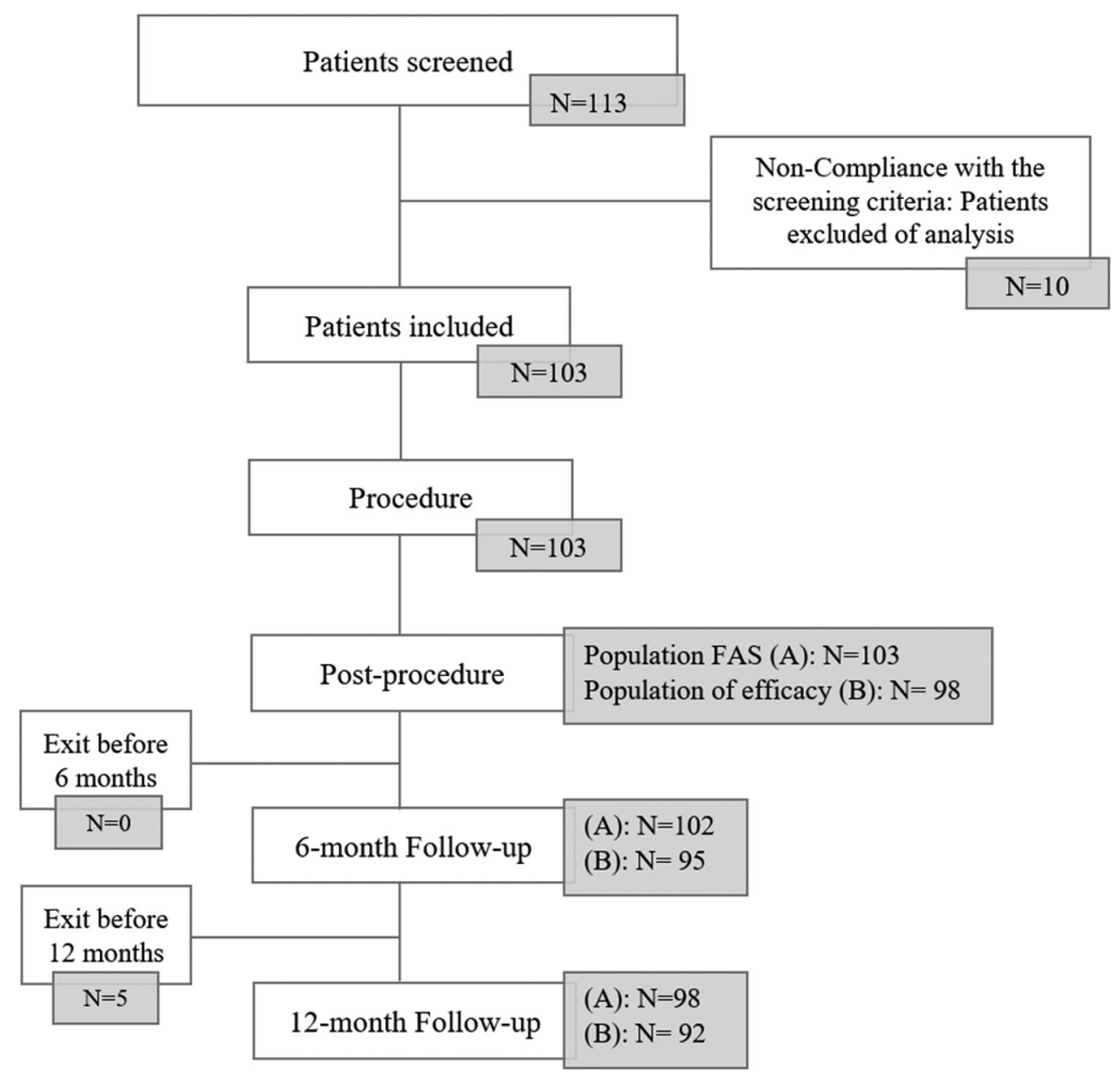

Figure 1 Flow chart of included patients and populations analysed: (A) full analysis set (FAS) for safety endpoint: all subjects who underwent treatment or attempted treatment with at least one FRED device; (B) population of efficacy: all subjects treated with FRED or FRED Jr device. Five patients were not implanted with the study device. Two patients died during the follow-up (perforation of the parent artery during intracranial catheterization 2 days after the procedure for the first patient, and lung cancer 10 months after the procedure for the second one). At 6 months, one patient did not complete the follow-up visit and one patient in a coma did not have control imaging performed. Five patients were withdrawn before 12 months: three were lost to follow-up, one withdrew consent, and one did not undergo the 12-month visit owing to non-implantation of the FRED device.

One patient was enrolled before initiation of the center. The final population included 103 patients (including 16 men: $15.5 \%$ and 87 women: $84.5 \%$ ). Ages ranged from 25 to 80 years (mean: $52.4 \pm 11.0$ years). The preoperative $\mathrm{mRS}$ score was 0 in 73 patients $(70.9 \%), 1$ in 25 (24.3\%), and 2 in 5 (4.9\%). No patient with multiple aneurysms was included.

Among the 103 aneurysms, 76 (73.8\%) were unruptured and $27(26.2 \%)$ recanalized. For recanalized aneurysms, initial treatment was coiling in $26 / 27$ patients $(96.3 \%)$ and clipping in 1 (3.7\%).

Aneurysm locations for Core Lab analysis were supraclinoid ICA in 71 (68.9\%), cavernous ICA in 15 (14.6\%), anterior cerebral artery or anterior communicating artery in $9(8.7 \%)$, and middle cerebral artery in $8(7.8 \%)$.

Aneurysms were small ( $<10 \mathrm{~mm}$ ) in 71 patients (68.9\%), large $(10-24 \mathrm{~mm})$ in $29(28.2 \%)$, and giant $(>24 \mathrm{~mm})$ in $3(2.9 \%)$. Neck was wide (neck $\geq 4 \mathrm{~mm}$ and/or dome-to-neck ratio $<2$ ) in 99 patients (96.1\%).

Preoperative, intraoperative, postoperative, 6-month, and 12 -month antiplatelet treatment is reported in table 1 . Antiplatelet activity testing was performed in only 52/103 patients $(50.5 \%)$.

\section{Treatment feasibility and adjunctive treatments}

Treatment was successfully performed in 98/103 patients (95.1\%).

Among the 98 patients effectively treated with a FRED or FRED Jr, 97 (99.0\%) were treated with one FRED (86) or FRED Jr (11) and one (1.0\%) was treated with two FRED Jr devices. Coils were placed in addition to FRED/FRED Jr in 22 patients $(22.4 \%)$ and a WEB intrasaccular device in two cases $(2.0 \%)$. In one patient, coils were used to occlude the parent vessel in a case of misdeployment of the FRED device.

\section{Complications with clinical impact up to 1 year}

Thromboembolic complications occurred in 7/103 patients (6.8\%), three during the procedure or immediately after (6 hours) and four after the procedure ( 1 and 4 days, and 7 and 14 months after). Aneurysms treated were large in two patients, small in three, and recanalized in two. Clinical outcome at 1 year was mRS score 0 in one patient, 1 in three, 2 in one, 3 in one, and 4 in one. One of these complications was related to the physician's decision to occlude the parent artery during the procedure owing to misdeployment of the device and was associated with an mRS score of 4 at 1 year. 

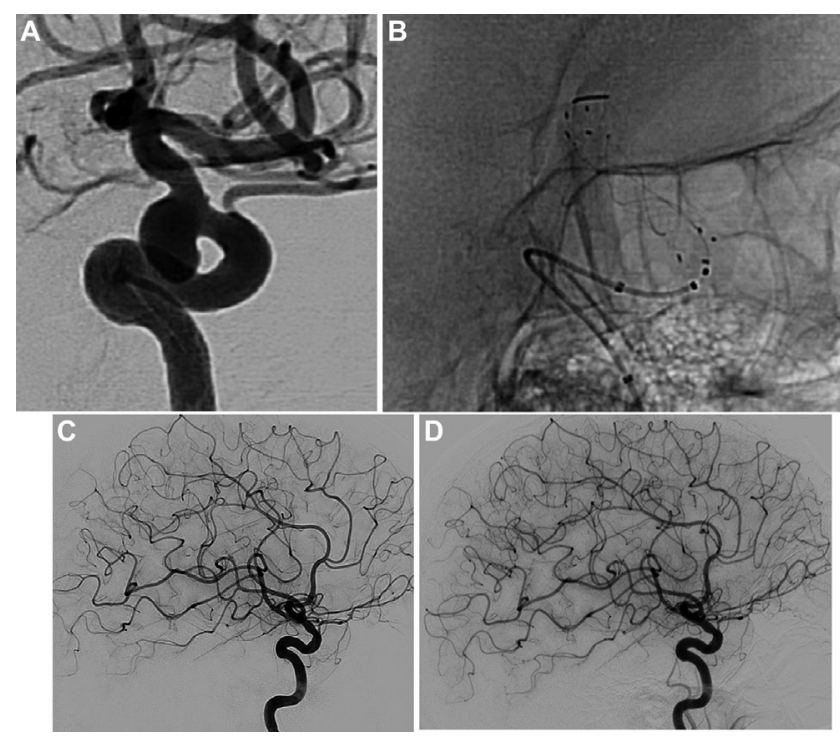

Figure 2 (A) Internal carotid artery/posterior communicating artery aneurysm. (B) Treatment with the FRED device. (C) Six-month control DSA shows complete aneurysm occlusion. (D) One-year control DSA shows complete aneurysm occlusion.

Intraoperative rupture occurred in 2/103 patients (1.9\%). One patient died 2 days after the procedure. The other patient had an mRS score of 0 at 12 months. Delayed aneurysm rupture was reported in $1 / 103$ patient $(1.0 \%)$ treated for a large $(20 \mathrm{~mm})$ supraclinoid aneurysm with FRED but no coils. Bleeding occurred 21 days after the procedure, associated with morbidity at 6 months (mRS score 5, coma). Delayed remote intraparenchymal hemorrhage occurred in $1 / 103$ patient $(1.0 \%)$ treated for a large supraclinoid ICA aneurysm. It was associated with strong initial clinical worsening and was surgically evacuated. Clinical evolution was favorable with mRS score 2 at 1 year.

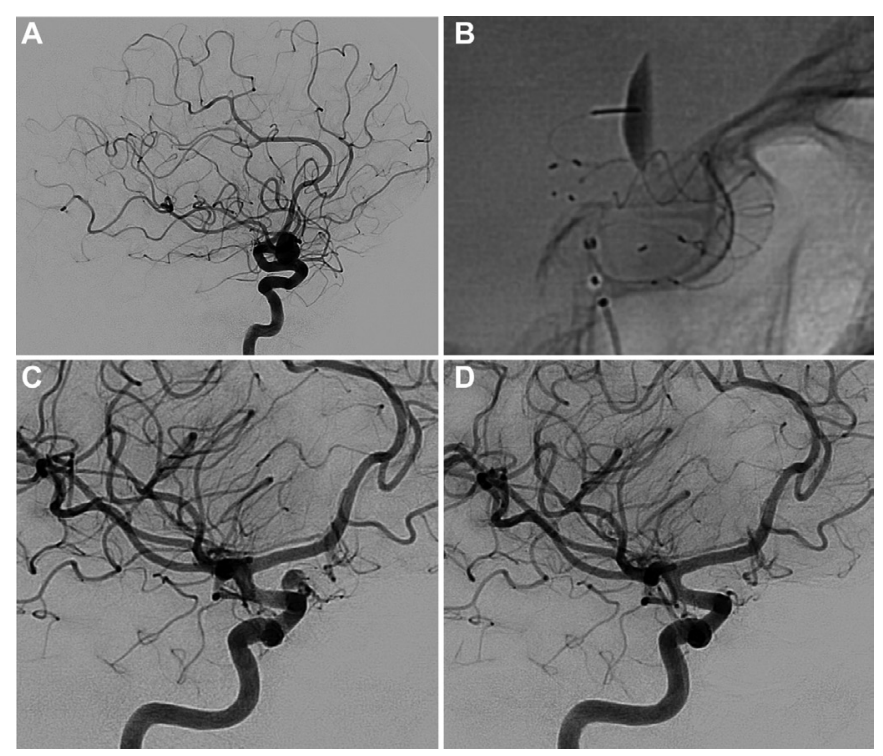

Figure 3 (A) Internal carotid artery/carotidophthalmic aneurysm. (B) Treatment with the FRED device. (C) Six-month control DSA shows an aneurysm remnant. (D) One-year control DSA shows complete aneurysm occlusion.
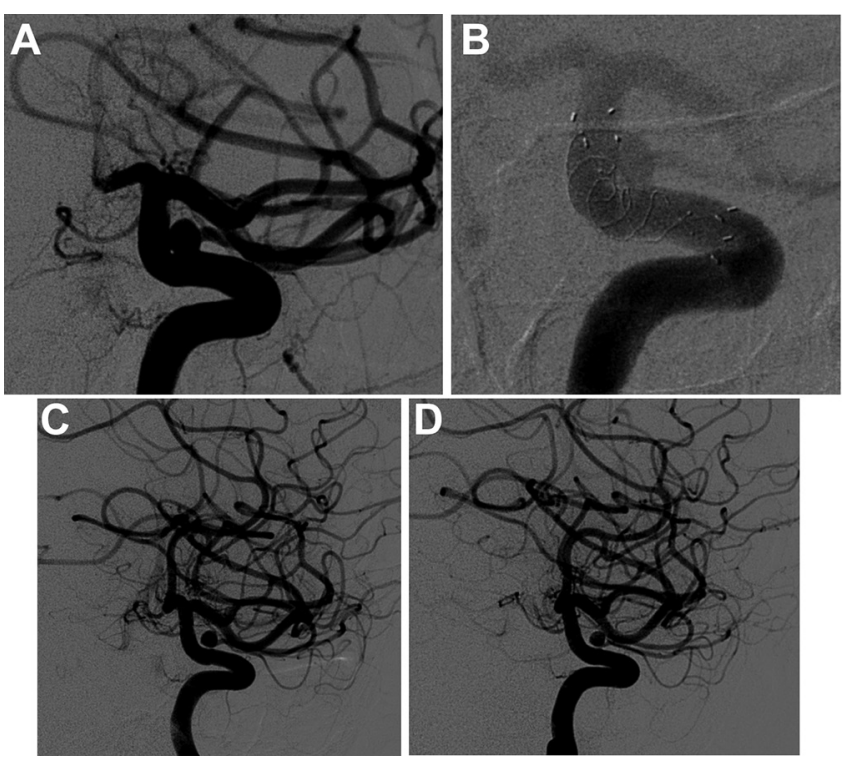

Figure 4 (A) Internal carotid artery/carotidophthalmic aneurysm. (B) Treatment with the FRED device. (C) Six-month control DSA shows an aneurysm remnant. (D) One-year control DSA shows an aneurysm remnant.

\section{Cumulated mortality/morbidity up to 1 year}

One-year follow-up was obtained in 98 patients (95.1\%). Missing data for early withdrawals $(n=3)$ were replaced by the last evaluation of mRS at 6 months. Two patients died before the end of the study.

Mortality rate was 2/103 (1.9\%). One patient had a perforation of the parent artery during intracranial catheterization and died (see above) and one patient died from lung cancer.

Morbidity rate was 3/103 (2.9\%). Morbidity was related to a thromboembolic complication in two patients with $\mathrm{mRS}$ scores of 3 and 4 at 1 year. One patient had a delayed hemorrhage 21 days after the procedure and was mRS 5 at 6 months (no evaluation performed at 1 year).

\section{Anatomical results at 6 months}

Anatomical results at 6 months (mean: $6.0 \pm 1.6$ months) were evaluated in $95 / 98$ patients $(96.9 \%)$.

The vascular imaging technique was digital subtraction angiography (DSA) in 81/95 (85.3\%) patients, and magnetic resonance angiography in 14/95 patients (14.7\%).

At 6 months, complete occlusion was observed in 58/95 aneurysms (61.1\%), neck remnant in 8/95 aneurysms $(8.4 \%)$, and aneurysm remnant in 29/95 aneurysms (30.5\%) (Figs 2, 3, and 4). Adequate occlusion (complete occlusion or neck remnant) was observed in 66/95 aneurysms (69.5\%). At 6 months aneurysm occlusion was improved in 78/95 aneurysms (82.1\%) and stable in $17 / 95(17.9 \%)$ since the postoperative assessment.

Table 1 Antiplatelet treatment before, during, immediately after, 6 months after, and 12 months after the procedure

\begin{tabular}{llllll}
\hline $\begin{array}{l}\text { Antiplatelet } \\
\text { medication }(\mathrm{n})\end{array}$ & $\begin{array}{l}\text { Before } \\
(\mathrm{n}=103)\end{array}$ & $\begin{array}{l}\text { During } \\
(\mathrm{n}=103)\end{array}$ & $\begin{array}{l}\text { After } \\
(\mathrm{n}=103)\end{array}$ & $\begin{array}{l}6 \text { Months } \\
(\mathrm{n}=101)\end{array}$ & $\begin{array}{l}12 \text { Months } \\
(\mathrm{n}=96)\end{array}$ \\
\hline 0 & $1(1.0 \%)$ & $4(3.9 \%)$ & $1(1.0 \%)$ & $25(24.8 \%)$ & $61(63.5 \%)$ \\
\hline 1 & $34(33.0 \%)$ & $52(50.5 \%)$ & $4(3.9 \%)$ & $71(70.3 \%)$ & $31(32.3 \%)$ \\
2 & $66(64.1 \%)$ & $42(40.8 \%)$ & $98(95.1 \%)$ & $5(5.0 \%)$ & $4(4.2 \%)$ \\
3 & $2(1.9 \%)$ & $5(4.9 \%)$ & $0(0.0 \%)$ & $0(0.0 \%)$ & $0(0.0 \%)$ \\
\hline
\end{tabular}

Pierot L, et al. J Neurolntervent Surg 2019;11:184-189. doi:10.1136/neurintsurg-2018-014261 
The status of the parent artery was evaluated for 94 patients (artefacts on the images made it impossible to assess in one patient), with results of no stenosis or stenosis $<50 \%$ in $87 / 94$ patients $(92.6 \%)$, stenosis $\geq 50 \%$ in $3 / 94$ patients $(3.2 \%)$, and complete occlusion in $4 / 94$ patients $(4.3 \%)$. Only one patient with intentional parent artery occlusion during the index procedure due to misdeployment of the FRED device was symptomatic with an mRS score of 4 at 6 months.

\section{Anatomical results at 1 year}

Anatomical results at 1 year (mean: $14.7 \pm 3.2$ months) were evaluated in 92/98 patients (93.9\%).

The vascular imaging technique was DSA in 54/92 (58.7\%) patients, CT angiography in $3 / 92$ patients $(3.3 \%)$, and magnetic resonance angiography in $35 / 92$ patients (38.0\%). Artefacts on the images made it impossible to assess the aneurysm occlusion in two patients, and parent artery patency in three patients.

At 1 year, complete occlusion was observed in 66/90 aneurysms (73.3\%), neck remnant in 7/90 aneurysms (7.8\%), and aneurysm remnant in 17/90 aneurysms (18.9\%) (Figs 2, 3, and 4). Adequate occlusion (complete occlusion or neck remnant) was observed in $73 / 90$ aneurysms $(81.1 \%)$. Of all the aneurysms evaluated, 72/90 occlusions (80.0\%) remained stable and 18/90 $(20.0 \%)$ had improved since the previous 6 month assessment. No worsening or recurrence was reported at 12 months.

The status of the parent artery was no stenosis or stenosis $<50 \%$ in $83 / 89$ patients $(93.3 \%$ ), stenosis $\geq 50 \%$ in $2 / 89$ patients $(2.2 \%)$, and complete occlusion in $4 / 89$ patients $(4.5 \%)$. Only one patient with parent artery occlusion performed according to the physician's decision during the index procedure owing to misdeployment of the FRED device was symptomatic, with an $\mathrm{mRS}$ score of 4 at 1 year.

\section{Retreatment}

At 1 year, 2/92 patients (2.2\%) were retreated (at 11.4 and 11.8 months). In both cases, the FRED device was initially properly placed in front of the neck. However, on the follow-up imaging the aneurysm was not occluded owing to incomplete coverage of the neck probably because of displacement or shortening of the device. Both aneurysms were successfully retreated with coils.

A third patient was retreated after 1 year (19.3 months) by placement of another flow diverter.

\section{DISCUSSION}

SAFE is the first prospective, multicenter study evaluating the safety and efficacy of the FRED device for aneurysm treatment. The preliminary results, including clinical follow-up at 6 months, were already showing the high feasibility (95.1\%) and good safety of the FRED device with 6-month morbidity of $2.0 \%$ and mortality $1.0 \%$ and a global rate of poor clinical outcome at $3.0 \%{ }^{16}$ The present analysis confirms the high safety of the FRED, with 1-year morbidity $2.9 \%$ and mortality $1.9 \%$. It also supports the high degree efficacy of the device, with 6-month and 1-year complete occlusion observed (Core Lab) in $61.1 \%$ and $73.3 \%$, respectively, and a very low retreatment rate at 1 year (2.2\%). Moreover, examination of the evolution of aneurysm occlusion between the postoperative period and 6 months shows that it is stable in $17.9 \%$ and improved in $82.1 \%$, indicating that aneurysm occlusion is a progressive phenomenon. Between 6 months and 1 year, aneurysm occlusion is stable in $80.0 \%$ and improved in $20.0 \%$.

If coiling is still the first-line treatment for both ruptured and unruptured intracranial aneurysms, it has some limitations.
Wide-neck aneurysms are difficult to treat with standard coiling, even with the assistance of the remodeling technique. ${ }^{17}$ Aneurysm coiling is also associated with a risk of aneurysm recanalization of roughly $20 \%$ and this risk is higher in large and giant aneurysms. ${ }^{18}$ These limitations have prompted the development of new techniques, including stent-assisted coiling, flow diversion, and flow disruption. ${ }^{2}$ Flow diversion is singularly useful for the treatment of large and giant aneurysms or wide-neck sidewall aneurysms. Initial clinical evaluation of the first available flow diverters (see below) showed good efficacy of this treatment at the price of a relatively poor safety profile. Further evaluation is needed with the new generation of flow diverters like the FRED now that the technique is more routinely used.

The problem of safety is potentially a limiting factor in the use of flow diversion. In the PUFS trial evaluating the Pipeline device (Medtronic, Minneapolis, Minnesota, USA) in large and giant aneurysms, major ipsilateral stroke or neurological death was observed in $5.6 \%$ of cases. ${ }^{4}$ Kallmes et al analyzed the safety and efficacy of the Pipeline device in the large pooled population of three studies (PUFS, IntrePED, and ASPIRe), which includes 1092 patients with 1221 aneurysms. $^{7}$ In that large series, the rates of major ipsilateral ischemic stroke and major ipsilateral intracranial hemorrhage were $3.7 \%$ and $2.0 \%$, respectively. Major neurological morbidity and neurological mortality occurred in 5.7\% and 3.3\%, respectively. The all-cause mortality rate was $4.0 \%$. In a prospective, multicenter series analyzing the results of aneurysm treatment with the Surpass device in 165 patients with 190 aneurysms (Stryker, Fremont, California, USA), permanent morbidity and procedure-related mortality were encountered in $6.0 \%$ and $2.7 \%$, respectively. ${ }^{19}$ In a retrospective, multicenter series, dealing with the treatment of intracranial aneurysms with the Silk flow diverter (Balt, Montmorency, France) in 157 patients with 180 aneurysms, 6-month total morbidity and mortality were $9.6 \%$ and $3.2 \%$, respectively. ${ }^{20}$ In this context, the FRED device demonstrates good primary safety outcomes (1-year global morbidity and mortality of $2.9 \%$ and $1.9 \%$, respectively), which compare favorably with those of other flow-diverter devices. However, comparing the safety of different flow diverters is difficult as patient and aneurysm populations often differ from one series to another, as do the precise modalities of treatment and perioperative medications.

Several factors can play a role in the high safety observed in SAFE, including the design of the study, the selection of the patients in the series, and the fact that this study was conducted in centers, which already have increased experience with flow diversion. Noticeably, the safety of aneurysm treatment is now, at least with the FRED device, very close to the safety of standard coiling as reported for example in ATENA (with 1-month morbidity and mortality of $1.7 \%$ and $1.4 \%$, respectively).

Flow diversion is one of the most efficacious endovascular techniques for treating intracranial aneurysms. Anatomical results in SAFE confirm the high effectiveness of treatment with FRED. According to Core Lab analysis, complete aneurysm occlusion is obtained in $61.1 \%$ at 6 months and $73.3 \%$ at 1 year. Similar results were reported in a large European retrospective series dealing with 531 patients and 579 aneurysms. ${ }^{21}$ In that series, the overall rate of complete aneurysm occlusion was $69.2 \%$ at 6 months and $91.3 \%$ at 1 year. These results are similar to those reported with other flow diverters. In the series dealing with aneurysms treated with the Surpass device, complete aneurysm occlusion was seen in $78.6 \%$ for anterior circulation. ${ }^{19}$ In the Silk series, complete aneurysm occlusion was observed in $78.1 \%$ at 12 months. In the pooled population of PUFS, IntrePED, and ASPIRe, complete aneurysm occlusion was reported in $75.0 \%$ 
at 6 months and $85.5 \%$ at 1 year. ${ }^{7}$ The slight difference between the different series for the rate of complete aneurysm occlusion is related to several different factors, including the population included in the series $(26.2 \%$ of aneurysms treated in SAFE are recanalized aneurysms), the modalities of treatment (most patients in SAFE were treated with one device when the use of multiple devices was very common in PUFS), and also the way in which anatomical results were evaluated (Core Lab or self-evaluation by the treating physician).

These results confirm that flow diversion is a highly efficacious technique associated with a very high rate of complete aneurysm occlusion that is not found with other techniques. They also confirm that, after flow diversion, aneurysm occlusion is a relatively slow process and that several months are sometimes necessary to obtain complete occlusion of the aneurysm. In the pooled analysis of IntrePED, PUFS, and ASPIRe, the rate of complete occlusion was $75.0 \%$ at 6 months, $85.5 \%$ at 1 year, $93.4 \%$ at 3 years, and $95.2 \%$ at 5 years. Also supporting the high efficacy of the FRED device, the rate of retreatment at 1 year is low $(2.2 \%)$ relative to the rate reported in the other series.

\section{Limitations}

The study has some limitations. First, SAFE is not a randomized trial and safety and efficacy cannot be directly compared with a control group. Second, most aneurysms were small, which is not the typical indication for flow diversion. However, we believe it was reasonably pragmatic to evaluate the FRED device in reallife practice.

\section{CONCLUSION}

The 1-year clinical data analysis in the SAFE study confirms the high degree of safety of the FRED device. Moreover, anatomical results demonstrate a high rate of complete occlusion at 6 months (61.1\%), which is still increasing at 1 year $(73.3 \%)$. The rate of adequate occlusion at 1 year is $81.1 \%$.

\section{Author affiliations}

'Hôpital Maison-Blanche, Université Reims-Champagne-Ardenne, Reims, France ${ }^{2}$ Paris-Saclay University, Hôpital Bicêtre, Assistance Publique-Hôpitaux de Paris, Paris, France

${ }^{3} \mathrm{CHU}$ Pellegrin, Bordeaux, France

${ }^{4} \mathrm{CHU}$ Toulouse, Toulouse, France

${ }^{5}$ Hôpital Bretonneau, Université François Rabelais, Tours, France

${ }^{6} \mathrm{CHU}$ Saint-Etienne, Saint-Etienne, France

${ }^{7}$ Fondation Ophtalmologique A. de Rothschild, Paris, France

${ }^{8}$ Hôpital Jean-Minjoz, CHRU de Besançon, Besançon, France

${ }^{9} \mathrm{CHU}$ Dupuytren, Limoges, France

${ }^{10}$ Hôpital Charles Nicolle, Université de Rouen, Rouen, France

${ }^{11} \mathrm{CHU}$ Lille, Lille, France

${ }^{12} \mathrm{CHU}$ Rennes, Rennes, France

${ }^{13} \mathrm{CHU}$ Nancy, Nancy, France

${ }^{14} \mathrm{CHU}$ Clermont-Ferrand, Clermont-Ferrand, France

${ }^{15}$ Hôpital Gui de Chauliac, Université de Montpellier, Montpellier, France

Contributors All authors have provided a substantial contribution to the conception and design of the studies and/or the acquisition and/or the analysis of the data and/or the interpretation of the data; drafted the work or revised it for significant intellectual content; approved the final version of the manuscript; agree to be accountable for all aspects of the work, including its accuracy and integrity.

Funding The SAFE study was funded by MicroVention Europe.

Competing interests LP is a consultant for Balt, Microvention, Neuravi, and Penumbra. LS is a consultant for Balt, Medtronic, Microvention, and Stryker. DH is a consultant for Codman, Medtronic, Sequent, and Stryker. MP is a consultant for Balt, Medtronic, Microvention, and Stryker. AB is a consultant for Balt, Medtronic,
Microvention, Stryker, and Phenox. XB is a consultant for Microvention, Sequent, and Stryker. VC is a consultant for Microvention and Balt and receives educational grants from Medtronic and Stryker.

\section{Patient consent Obtained.}

Provenance and peer review Not commissioned; externally peer reviewed.

Open access This is an open access article distributed in accordance with the Creative Commons Attribution Non Commercial (CC BY-NC 4.0) license, which permits others to distribute, remix, adapt, build upon this work non-commercially, and license their derivative works on different terms, provided the original work is properly cited, appropriate credit is given, any changes made indicated, and the use is non-commercial. See: http://creativecommons.org/licenses/by-nc/4.0/.

\section{REFERENCES}

1 Pierot L. Flow diverter stents in the treatment of intracranial aneurysms: where are we? J Neuroradio/ 2011;38:40-6.

2 Pierot L, Wakhloo AK. Endovascular treatment of intracranial aneurysms: current status. Stroke 2013;44:2046-54.

3 Walcott BP, Stapleton CJ, Choudhri 0, et al. Flow diversion for the treatment of intracranial aneurysms. JAMA Neurol 2016;73:1002-8.

4 Becske T, Kallmes DF, Saatci I, et al. Pipeline for uncoilable or failed aneurysms: results from a multicenter clinical trial. Radiology 2013;267:858-68.

5 Kiyofuji S, Graffeo CS, Perry A, et al. Meta-analysis of treatment outcomes of posterior circulation non-saccular aneurysms by flow diverters. J Neurointerv Surg 2018:10:493-9.

6 Pierot L, Biondi A. Endovascular techniques for the management of wide-neck intracranial bifurcation aneurysms: a critical review of the literature. J Neuroradiol 2016:43:167-75

7 Kallmes DF, Brinjikji W, Cekirge S, et al. Safety and efficacy of the pipeline embolization device for treatment of intracranial aneurysms: a pooled analysis of 3 large studies. J Neurosurg 2017;127:775-80.

8 Benaissa A, Januel AC, Herbreteau D, et al. Endovascular treatment with flow diverters of recanalized and multitreated aneurysms initially treated by endovascular approach. J Neurointerv Surg 2015:7:44-9.

9 Pumar JM, Mosqueira A, Cuellar H, et al. Expanding the use of flow diverters beyond their initial indication: treatment of small unruptured aneurysms. J Neurointerv Surg 2018; 10:245-8.

10 Bhogal P, Ganslandt O, Bäzner H, et al. The fate of side branches covered by flow diverters-results from 140 patients. World Neurosurg 2017;103:789-98.

11 Benaissa A, Tomas C, Clarençon F, et al. Retrospective analysis of delayed intraparenchymal hemorrhage after flow-diverter treatment: presentation of a retrospective multicenter trial. AJNR Am J Neuroradio/ 2016;37:475-80.

12 Briganti $F$, Leone $G$, Ugga $L$, et al. Safety and efficacy of flow re-direction endoluminal device (FRED) in the treatment of cerebral aneurysms: a single center experience. Acta Neurochir 2016;158:1745-55.

13 Drescher F, Weber W, Berlis A, et al. Treatment of intra- and extracranial aneurysms using the flow-redirection endoluminal device: multicenter experience and follow-up results. AJNR Am J Neuroradiol 2017;38:105-12.

14 Luecking $\mathrm{H}$, Engelhorn $\mathrm{T}$, Lang $\mathrm{S}$, et al. FRED flow diverter: a study on safety and efficacy in a consecutive group of 50 patients. AJNR Am J Neuroradiol 2017:38:596-602.

15 Möhlenbruch MA, Kizilkilic O, Killer-Oberpfalzer M, et al. Multicenter experience with FRED Jr Flow re-direction endoluminal device for intracranial aneurysms in small arteries. AJNR Am J Neuroradiol 2017:38:1959-65.

16 Pierot L, Spelle L, Berge J, et al. Feasibility, complications, morbidity, and mortality results at 6 months for aneurysm treatment with the Flow Re-Direction Endoluminal Device: report of SAFE study. J Neurointerv Surg 2018;10:765-70.

17 Pierot L, Cognard C, Spelle L, et al. Safety and efficacy of balloon remodeling technique during endovascular treatment of intracranial aneurysms: critical review of the literature. AJNR Am J Neuroradiol 2012:33:12-15.

18 Benaissa A, Barbe C, Pierot L. Analysis of recanalization after endovascular treatment of intracranial aneurysm (ARETA trial): presentation of a prospective multicenter study. J Neuroradiol 2015;42:80-5.

19 Wakhloo AK, Lylyk P, de Vries J, et al. Surpass flow diverter in the treatment of intracranial aneurysms: a prospective multicenter study. AJNR Am J Neuroradiol 2015;36:98-107

20 Pumar JM, Banguero A, Cuellar $\mathrm{H}$, et al. Treatment of intracranial aneurysms with the SILK embolization device in a multicenter study. a retrospective data analysis. Neurosurgery 2017:81:595-601.

21 Killer-Oberpfalzer M, Kocer N, Griessenauer CJ, et al. European multicenter study for the evaluation of a dual-layer flow-diverting stent for treatment of wide-neck intracranial aneurysms: the European flow-redirection intraluminal device study. AJNR Am J Neuroradiol 2018;39:841-7. 